\title{
INFLUENCE OF CARDBOARD COATING ON SOLVENT RETENTION
}

\author{
ELIZA ANGELI ${ }^{*, * *}$ and ROZÁLIA SZENTGYÖRGYVÖLGYI ${ }^{* * *}$ \\ *Obuda University, Doctoral School on Materials Sciences and Technologies, \\ 6 Doberdo ut, 1034 Budapest, Hungary \\ ** John von Neumann University, GAMF Faculty of Engineering and Computer Science, \\ 10 Izsaki ut, 6000 Kecskemet, Hungary \\ ${ }^{* * *}$ Obuda University, Rejto Sandor Faculty of Light Industry and Environmental Engineering, \\ 6 Doberdo ut, 1034 Budapest, Hungary
}

Received July 7, 2019

Packaging has a barrier function between the product and the environment. Flavour and taste changes in food products due to the transfer of undesirable volatile compounds from gravure printed cardboard packaging should be avoided. In this study, the influence of cellulose-based, folding boxboard (FBB) type cardboard coating on solvent retention was studied by gas chromatography (GC). FBB samples with 1-3 and no coating layers on the top side, and with coated or uncoated back side, were printed by rotogravure. Then, solvent retention was measured at 3 different time intervals. Ethanol and ethyl acetate contents were studied more in depth in order to obtain information on the emission behavior of alcohol and ester type solvents from the cellulose-based cardboard. Based on GC results, ethanol and ethyl acetate retention ratios were calculated and then normalized to coating thickness for every time interval, aiming to see the solvent retention differences as a function of the number of coating layers applied onto the cardboard surface. It was found that the number of coating layers on the cellulose-based cardboard top and back sides has a clear influence on solvent retention and emission on/from printed packaging. Therefore, it can be considered as a significant variable in solvent retention analysis.

Keywords: folding boxboard, coating, solvent retention, emission, gravure printing, gas chromatography

\section{INTRODUCTION}

Paper and paperboard are widely used as packaging material in many different industries, covering as a base material about the one third of the total packaging market. Over $50 \%$ of the paper and paperboard packaging is manufactured for the food industry. Packaging has two important functions in the food industry: to advertise and to protect the packed food products from quality deterioration caused by external agents. The quality and safety of food might be negatively influenced by the transfer of chemicals originating from many sources, including migration from packaging. Specifically, the aroma absorption and transfer of undesirable volatile compounds from polymer-based printed packaging to foods can cause consumer health problems and incur changes in product taste and odor. Therefore, the printing of packaging that comes in contact with food is required to meet severe food industrial standards. A low concentration of undesirable materials in the packaging material is the pledge of low migration into foodstuff. The chemical compounds content of printed packaging is usually measured by the gas chromatography (GC) technique, which is a highly advanced technique for the analysis of substances. ${ }^{1-4}$

Cellulose-based packaging materials printed by the gravure technology are widely spread in the food industry. High quality and consistent printing of complex designs can be easily achieved by the high-speed gravure printing technology. The ink used in gravure printing has low viscosity and contains colorants (dyes or pigments), binders (resins or plastics), additives and a high proportion of volatile solvents (alcohols, esters, aliphatic and aromatic compounds, glycols, ketones). The liquid ink in the cells of a metal-based image cylinder can be properly transferred onto the substrate surface by high pressure. The printed substrate passes through a heated high velocity air dryer to remove the majority of the solvents by evaporation. After drying, a part of the solvents still remains in the ink and absorbed into the cardboard from the ink layer. This is the solvent retained in the substrate, called solvent retention. Figure 1 shows the solvent-based gravure ink absorption and 
evaporation drying principle. Volatile solvents are particularly important in gravure technology, and are used in order to set low viscosity and change pigment concentration and ink density. Complex designs, increased use of metallic inks (thicker ink film layers are required) and high production speed on rotogravure machines, which are common trends nowadays, make it difficult to keep solvent retention of gravure printed packaging low. ${ }^{5-9}$

In a series of investigations, we aimed to study the main components and properties of cellulosebased, folding boxboard that have an influence on solvent resistance. In a previous study, we examined how the cardboard moisture content has an effect on solvent retention of gravure printed folding boxboard. ${ }^{9}$ In this work, the influence of cardboard coating on solvent retention of cellulose-based gravure printed packaging was studied.

Paperboard grades are classified into three categories: cardboards, containerboards and specialty boards. Paperboard basis weight is usually higher than $150 \mathrm{~g} / \mathrm{m}^{2}$. Cardboard is the common name for the paper substrate used for packaging, and it contains three or more pulp layers simultaneously produced on a multilayer paperboard machine. Cardboards are devided into five subgrades: folding boxboard (FBB), solid bleached board (SBB), solid unbleached board (SUB), liquid packaging board (LPB) and white lined chipboard (WLC). The folding boxboard type cardboard is used worldwide in the packaging industry, in the grammage range of $160-450 \mathrm{~g} / \mathrm{m}^{2}$. FBB is a multiply cardboard, typically made of three pulp plies: top ply chemical pulp (bleached softwood or bleached hardwood pulps); middle ply - mechanical pulp

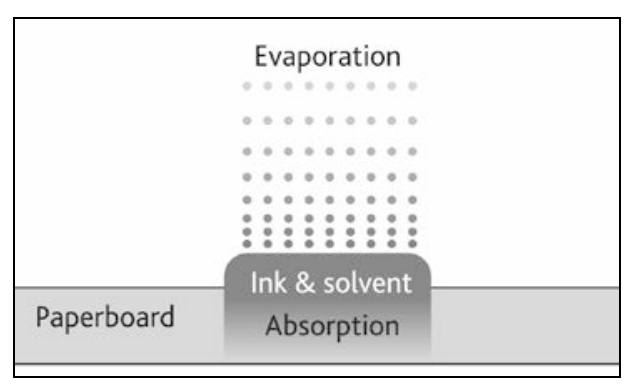

Figure 1: Ink absorption and evaporation principle (groundwood, pressure groundwood, thermomechanical pulp) or CTMP (chemi-thermomechanical pulp); back ply - chemical pulp (bleached softwood or bleached hardwood pulps). Depending on the end-use requirements, the top side of FBB can be single, double or triple coated, while the back side can be single coated or uncoated. Folding boxboard is mainly used for manufacturing packaging materials for food, confectionery, cosmetics, tobacco and pharmaceutical industrial segments. ${ }^{10-12}$ A typical multilayer structure of FBB type cardboard can be seen in Figure 2.

Cardboard grades are usually white mineral pigment coated in order to achieve good printed quality and improve substrate properties. The coating fills the cavities and covers the highest sitting fibers on the surface of the cardboard substrate; however, flaws cannot be completely hidden. The printing ink penetration into the cardboard is reduced by the coating layer; consequently, the ink does not spread too much and the print image stays clear and sharp. Coating is an aqueous suspension containing several components: pigments (kaolin clay, calcium carbonate, talc), binders (starch, SB-latex, acrylate latex, CMC), additives (lubricant, insolubilizer, optical brightening agents) and water. The most important coating color component is the pigment, which can be mineral or synthetic. The share of pigments in the dry coating is about $80-95 \%$ of the coating by weight. Another important coating color component is the binder, which has the function to glue pigment particles to the cardboard surface and also to bind pigment particles to each other. Usually, the binder amount in the dry coating color is about 5$20 \%$ of the coating by weight.

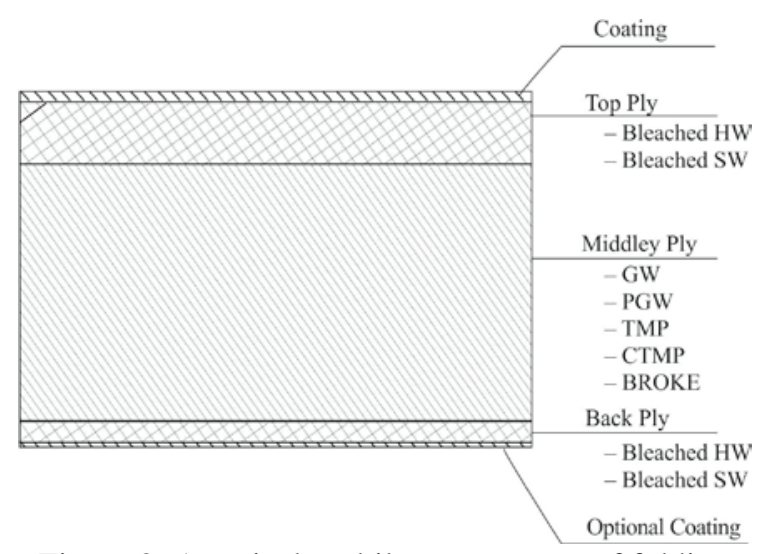

Figure 2: A typical multilayer structure of folding boxboard type cardboard 


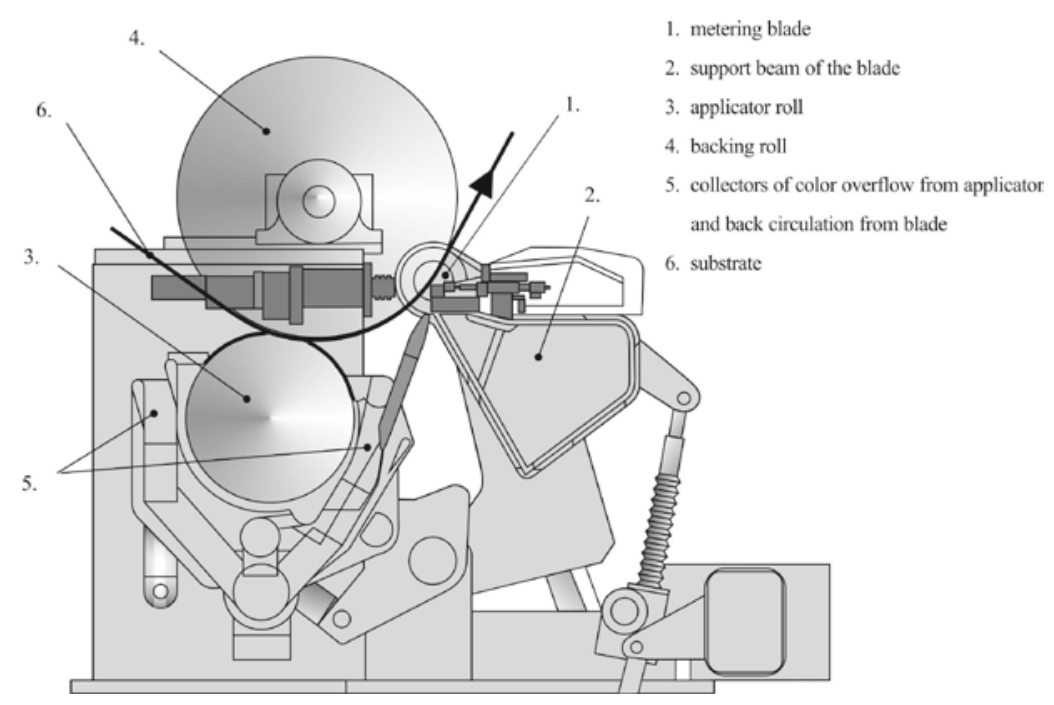

Figure 3: Principle of paperboard blade coating

There are various additives with different functions (e.g. adjusting $\mathrm{pH}$, optical brightening) in the coating color mixture, with the share of $2 \%$ of the coating by weight when dry. Water is a

Depending on the end-user requirements and printing purposes, various numbers of coating layers can be applied to the substrate surface on the top and back sides, with $10-15 \mathrm{~g} / \mathrm{m}^{2}$ coating weight per layer. Then, the coating layer(s) is/are dried and finished. There are single (1 layer), double (two layers) and multiple (three or more) coatings, depending on the number of coating layers applied. The effects of coating on the cardboard can be: to decrease ink absorption, mechanical strength, dusting and stiffness; to improve smoothness, gloss, opacity and brightness; to increase surface strength. ${ }^{13-16}$

Coatings can also differ according to the way coating color is applied to the cardboard surface, thus blade, roll, rod and air-jet coatings are known. The top side of FBB type cardboard is generally double or triple blade coated; the back side can be coated, or usually remains uncoated, according to the printing and design requirements. Figure 3 shows the principle of blade coating. ${ }^{13}$

This paper analyzed the effect of coating layers, which are extremely important in high quality printing, applied to cellulose-based cardboard produced from bleached chemical pulp (top ply and back ply) and CTMP (middle ply). Furthermore, this work investigated the retention and emission of the solvents used as part of the printing ink mixture on/from the printed packaging. basic part of the coating color, with the function of mixing the components, transporting and applying the pigment particles to the cardboard surface.

\section{EXPERIMENTAL}

Cardboard samples of folding boxboard type, with CTMP in the middle layer, were used for this study. Table 1 shows the analyzed cardboard types and properties. White mineral pigment coating layers (in different numbers: 1, 2, 3 or no coating layers on the top side and coated or uncoated back side) were applied on the cardboard surface by the blade coating method, using the blade coater of a paperboard manufacturing machine. The coating color applied to the cardboard surface contained the following: pigments (kaolin clay 30\%, calcium carbonate $70 \%$ ), binder (SB-latex), additives (lubricant, insolubilizer) and water. The thickness of the coating color per layer was on average of $3.14 \mu \mathrm{m}$, as determined from SEM images. This value is the average of 5 measurements.

The cardboard samples, with different numbers of coating layers on the top and back sides, were test printed on a Bobst Lemanic 650 rotogravure machine. Table 2 shows the test print parameters and gravure press set-up: ink types, solvent types and ratio in ink, viscosity.

After the FBB samples were printed by rotogravure, their solvent retention was assessed. As the quality and safety of food might be negatively influenced by the transfer of volatile solvents from the packaging to the food, we focused on the critical solvents, such as ethanol and ethyl acetate, and on the role and importance of the FBB substrate coating. The retained ethanol and ethyl acetate content was measured, and based on the obtained figures, the solvent retention ratio was calculated. Then, the calculated value was normalized to the average coating 


\section{ELIZA ANGELI and ROZÁLIA SZENTGYÖRGYVÖLGYI}

thickness of the samples in order to avoid the interference of disturbing factors, such as printed design alteration, and to see the solvent emission intensity. As the majority of compounds causing offflavour and taint problems in printed packaging are volatile, the best analytical instrumentation that can be used to detect solvent retention amounts is gas chromatography. In GC technique, chemicals are separated in a complex sample, whereas the sample is vaporized and inserted onto the head of the chromatographic column in order to investigate the volatile compounds. In the headspace-gas chromatography (HS-GC) process, the liquid or solid sample is put in a vial that has a gas volume above it and then closed. In order to reach the equilibrium between the two phases, the vial is thermostated at a constant temperature. Then, the headspace (an aliquot of the vial's gas phase) is inserted into the carrier gas stream, which delivers it into the column, where it is analysed. $^{18,19}$

Table 1

FBB type cardboards with different numbers of coating layers on top and back sides

\begin{tabular}{ccc}
\hline \multirow{2}{*}{$\begin{array}{c}\text { Cardboard } \\
\text { samples }\end{array}$} & $\begin{array}{c}\text { Number of coating layers, } \\
10 \mathrm{~g} / \mathrm{m}^{2} \text { per layer }\end{array}$ & $\begin{array}{c}\text { Grammage, } \\
\mathrm{g} / \mathrm{m}^{2}\end{array}$ \\
\cline { 2 - 2 } & Top side & 225 \\
A* & 3 & 215 \\
B & 3 & 215 \\
C & 3 & 205 \\
D & 2 & 195 \\
E & 1 & 185 \\
F & 0 & \\
\hline
\end{tabular}

*Backside coated (1 layer)

Table 2

Test printing parameters and machine set-up

\begin{tabular}{lccc}
\hline Printing parameters & \multicolumn{3}{c}{ Printing units } \\
\cline { 2 - 4 } Cylinder type & Laser engraved & $\begin{array}{c}\text { Mechanically } \\
\text { engraved }\end{array}$ & Full tone varnish \\
$\begin{array}{l}\text { Drying temperature, }{ }^{\circ} \mathrm{C} \\
\text { Speed, } \mathrm{m} / \mathrm{min}\end{array}$ & 50 & 50 & 125 \\
Pressure, $\mathrm{kN}$ & & 100 & 16 \\
Ink type & 17 & 16 & Varnish \\
Solvent ratio & Basic green & Basic blue & Ethanol 25\% \\
in ready-made ink & Ethanol 25\% & Wthyl acetate $75 \%$ & Water-based 100\% \\
Viscosity, s & Ethyl acetate 75\% & 15.5 & - \\
\hline
\end{tabular}

Solvent retention was measured at 3 different time intervals: right after printing, 1 day and 7 days after printing, using Agilent 6890N gas chromatography equipment. Samples of $50 \mathrm{~cm}^{2}$ were cut from the printed samples (with the same part of the printed design in every sampling), and then each sample was further cut into smaller 12 pieces. All the obtained sample pieces were quickly put into a $25 \mathrm{~mL}$ vial and 1 $\mathrm{mL}$ matrix solution (triacetin) was added and the vial was closed tightly. Three sets of samples were prepared the same way at every experimental point. The prepared vials were then placed quickly into the headspace, which was then heated up to the specified temperature until it reached the phase equilibrium. Via the transfer line, the vapour phase sample was introduced to the GC column; the sample was separated, its composition was detected and quantified by a flame ionization detector (FID). The set-up parameters of the Agilent 6890N gas chromatography equipment were as follows: column: $30 \mathrm{~m}, 0.53 \mathrm{~mm}$ i.d., $5.0 \mathrm{~mm}$ non polar phase; carrier gas: Helium, pressure optimised for peak resolution. The temperatures of the split injector and detector were optimized. The configuration of the method: last vial 40, headspace mode constant; oven, needle and transfer temperatures were optimized in the range of 100-150 ${ }^{\circ} \mathrm{C}$. In order to obtain a sufficient amount of solvent compounds for gas chromatography detection, the GC cycle, thermostating time, headspace pressure, pressurization time and injection time had to be optimized. The retained solvent concentrations of the printed packaging samples were reported in $\mathrm{mg} / \mathrm{m}^{2}$. At every experimental point, 3 GC measurements were performed, and the results were averaged. ${ }^{9,17}$ 


\section{RESULTS AND DISCUSSION}

The solvent evaporation mechanism of ethanol and ethyl acetate from the cardboard is likely to consist of several sub-processes: the solvent molecule is desorbed from the solvate shell, the desorbed molecule is diffused to the surface, and then the solvent molecule is desorbed from the surface. The porosity of the cardboard will determine a reduction of the diffusion pathway. However, it should also be considered that the concentration of the solvent in the pores will be provided by desorption and adsorption (there is a concentration gradient towards the outer surface, which is the driving force). This process might also be characteristic of the coating. Upon reaching the interface, the solvent molecule might dissolve into the coating layer, through which it passes by diffusion and then desorbs from the surface. Since the coating layer is non-porous, it has much higher resistance.

\section{Ethanol retention ratio}

In order to assess the influence of backside coating on ethanol retention, gravure printed topside coated (3 layers) cardboard samples were investigated with coated and uncoated backsides. In Figure 4, scanning electron microscopy (SEM) images of the investigated samples, with coated (A) and uncoated (B) backside surfaces can be seen.

Based on the ethanol retention results measured by the GC method at 3 different time intervals: right after printing, 1 day and 7 days after printing, the normalized ethanol retention ratio was calculated and shown in Figure 5. As can be noted, there are two phases in the ethanol emission process: the first, quick phase takes one day, when the ethanol molecules leave the cardboard coating surface intensively; and the second, slow phase takes 6 days, when the ethanol molecules positioned below the coating layers leave the cardboard moderately - this might be a diffusion controlled process. The backside coating has a negative impact on ethanol retention, as the retained solvent amount was higher when one coating layer was applied to the cardboard backside surface, compared to the sample that had no coating on the reverse side. Considering that ethanol generally has a relatively fast evaporation speed, most of the ethanol molecules are released from the cardboard in the first phase (in 1 day), then the evaporation slows down significantly and the remaining ethanol amount evaporates in 6 days.

To examine the effect of the topside coating on ethanol retention, four gravure printed FBB type cardboard samples, with uncoated back side and with $3,2,1,0$ coating layers on the top side (samples C, D, E and F), were investigated. Ethanol retention of the samples was measured by GC at different time intervals after printing, and then the normalized ethanol retention ratio was calculated. As observed in the first experiment, the two process phases of ethanol emission can be also remarked (Fig. 6): the first, one-day long quick phase, when the ethanol emission was intensive; and the second, 6-day long slow phase, which might also be a diffusion controlled process, when the ethanol left the cardboard moderately.

It is evident from the normalized ethanol retention ratio diagram that the presence of the top coating layers has a clear impact on the ethanol amount retained in the gravure printed cardboard packaging. When the number of coating layers increased on the cardboard top side, a higher amount of ethanol was present in the substrate. Presumably, the ethanol emission was more obstructed by the coating, when the number of coating layers, and thus the coating weight, increased. The difference is significant when the third coating layer was applied, as a thicker coating closes the pores of the cardboard surface more tightly, blocking the evaporation of ethanol.

\section{Ethyl acetate retention ratio}

In this experiment, the effect of backside coating on ethyl acetate retention was investigated on top side coated (3 layers), gravure printed cardboard samples, with coated (A) and uncoated (B) backsides. The retained ethyl acetate amount was measured by the GC method at 3 time intervals: right after printing, 1 day and 7 days after printing. The ethyl acetate retention ratio was then normalized in order to see the solvent emission characteristics. The previously observed two phases of the evaporation process (fast phase (1 day) and slow phase (6 days)) can be also clearly seen in Figure 7, which illustrates the release of acetate molecules from the cardboard. Right after printing, the ethyl acetate retention of sample B (backside uncoated) and sample A (backside coated) were notably high, but both decreased remarkably 1 day after printing. 


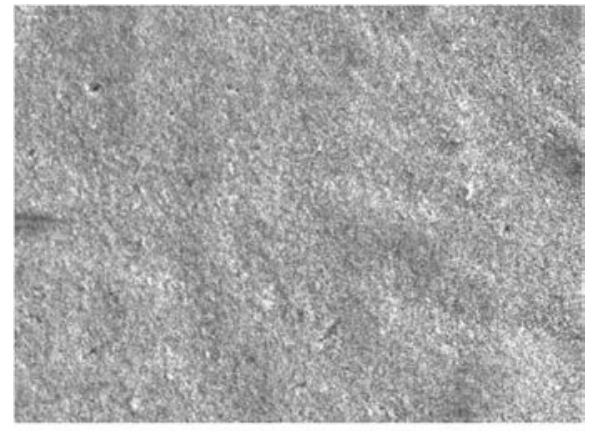

1.

\begin{tabular}{lll}
\hline $100 \mu \mathrm{m}$ & EHT $=20.00 \mathrm{kV}$ & Signal A $=$ SE 1 \\
& WD $=27.0 \mathrm{~mm}$ & Mag $=500 \mathrm{X}$
\end{tabular}

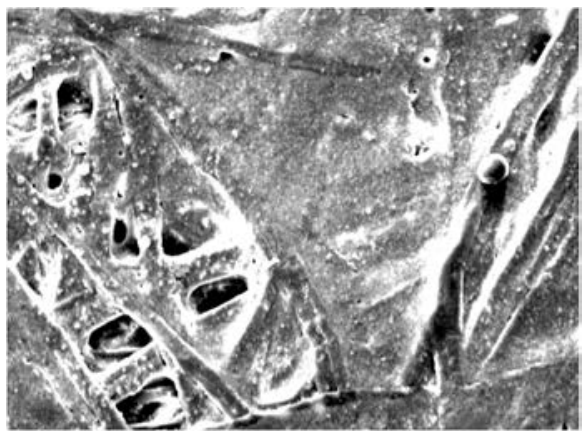

2.

$\begin{array}{lll}100 \mu \mathrm{m} & \begin{array}{l}\text { EHT }=20.00 \mathrm{kV} \\ \text { WD }=26.5 \mathrm{~mm}\end{array} & \begin{array}{l}\text { Signal A }=\text { SE } 1 \\ \text { Mag }=500 \mathrm{X}\end{array}\end{array}$

Figure 4: SEM images of coated (1) and uncoated (2) FBB type cardboard surface

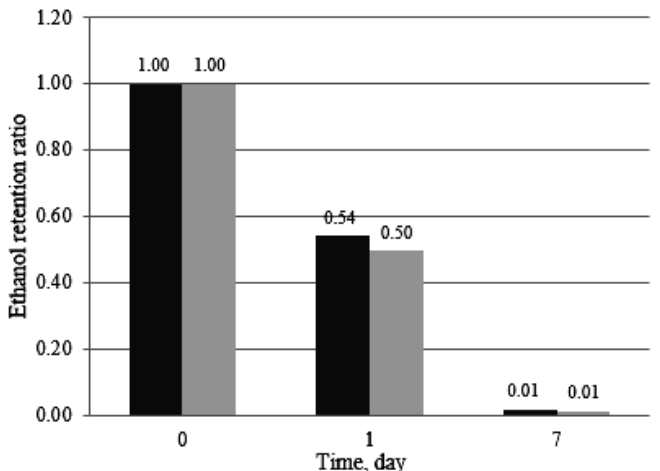

Figure 5: Normalized ethanol retention ratio of topside coated (3 layers) cardboards with coated (A) and uncoated (B) backside, measured at different time intervals

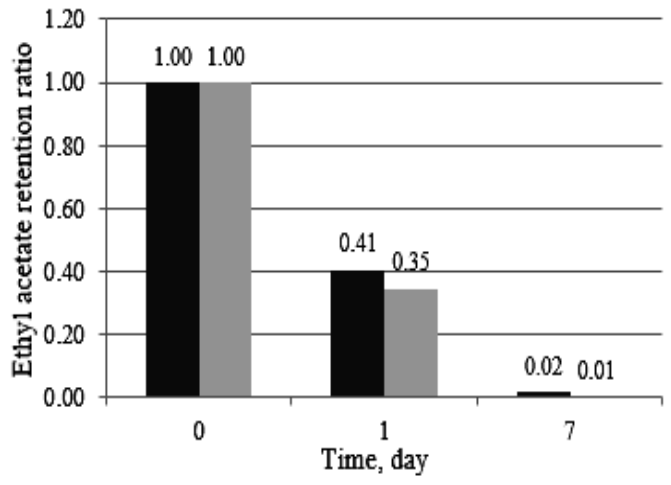

- Board A

Backside coat - Board B

Backside uncı

Figure 7: Normalized ethyl acetate retention ratio of topside coated (3 layers) cardboards with coated (A) and uncoated (B) backside, measured at different time intervals

Nevertheless, the retained ethyl acetate amount was higher in the sample with backside coating. The top and back side coating layers cover the

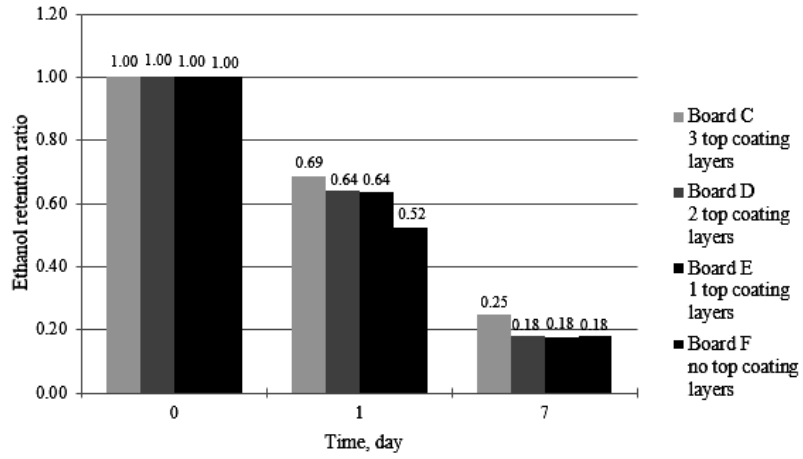

Figure 6: Normalized ethanol retention ratio of backside uncoated cardboards with 3, 2, 1, 0 topside coating layers (C, D, E and F), measured at different time intervals

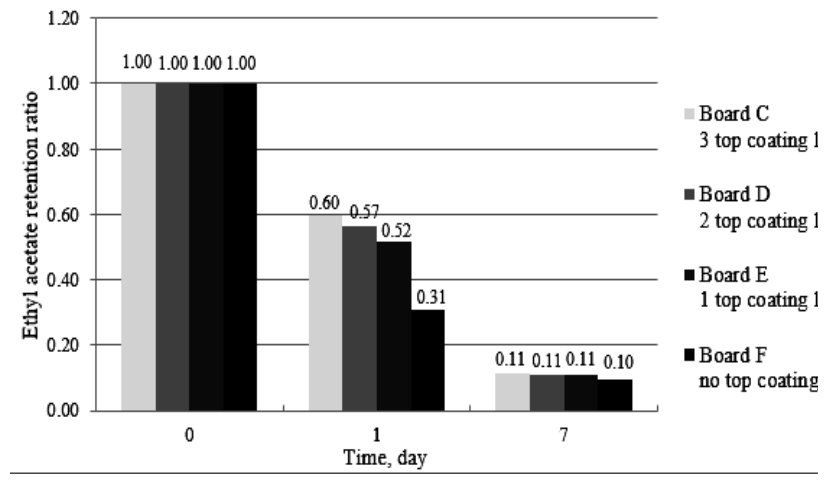

Figure 8: Normalized ethyl acetate retention ratio of backside uncoated cardboards with 3, 2, 1, 0 topside coating layers (C, D, E and F), measured at different time intervals

cardboard surface, closing its pores, therefore, the coating might slow down the emission of the acetate from the printed substrate. It is evident 
from the figures that backside coating has a negative impact on the ethyl acetate emission of gravure printed FBB type cardboard.

The effect of the top coating on ethyl acetate retention was examined in the next experiment, where four gravure printed cardboard samples, with uncoated backside and with 3, 2, 1, 0 coating layers on the top side (samples C, D, E and F) were investigated. The ethyl acetate retention ratio of the samples was calculated based on the retained ethyl acetate amounts measured by GC at 3 different time intervals after printing, and the results were normalized. As observed, ethyl acetate is a more critical solvent in terms of its retention levels, compared to ethanol, as it has a lower evaporation speed and could take more than a week for high amounts of ethyl acetate retained in gravure printed FBB cardboard to decrease to zero level. Figure 7 shows that this was the case in our fourth experiment. Notably, the two evaporation process phases (slow and fast phases) can be also recognized in Figure 8.

With an increasing number of coating layers on the cardboard top side, a higher amount of ethyl acetate was retained in the substrate. As mentioned above, in this case, it can be stated as well that a higher number of coating layers applied to the board top surface leads to blocking the evaporation of a higher amount of ethyl acetate, consequently, the acetate emission intensity decreased. It can be thus concluded that the top side coating layers of the cardboard have an obvious impact on ethyl acetate retention.

Table 3

Solvent reduction rates normalized to coating layer thickness for samples A-F

\begin{tabular}{cccc}
\hline Cardboard & $\begin{array}{c}\text { Number of top coating layers } \\
\text { samples }\end{array}$ & \multicolumn{2}{c}{$\xi, \mathrm{mg} / \mathrm{m}^{2} / \mu \mathrm{m} /$ day } \\
\cline { 3 - 4 } (av. 3.14 $\mu \mathrm{m} /$ layer) & Ethanol & Ethyl acetate \\
\hline F & 0 & 0.035 & 0.054 \\
E & 1 & 0.022 & 0.021 \\
D & 2 & 0.012 & 0.012 \\
C & 3 & 0.007 & 0.006 \\
A & $3+1^{*}$ & 0.005 & 0.004 \\
\hline Backside coating & & &
\end{tabular}

Based on the solvent retention ratio figures calculated in the above experiments, the ethanol and ethyl acetate reduction rates were normalized to coating layer thickness of the gravure printed FBB board samples, in order to examine the effect of coating layer thickness on the retained critical solvents. It can be clearly seen in Table 3 that by increasing the number of coating layers on the cardboard samples top side, the ethanol and ethyl acetate evaporation was slowed down $(\xi)$. It is worthy of note that the average value of the coating layer thickness showed remarkable variation, which might have an influence on the evaporation and diffusion controlled processes on and below the coated surface. It was also observed that sample A exhibited the slowest solvent evaporation rate. This can be explained by the fact that it was coated on both sides, and thus its pores were closed on both the top and back surfaces, obstructing the evaporation of the solvents.

The different values shown in Table 3 suggest that the evaporation of solvents through the coating layers depends on the coating thickness, while it should be independent of it. The difference presumably comes from the coating layer non-uniformity, including variation in the thickness of the layers. However, the importance of the coated surface structure, namely the number of coated layers applied, has been confirmed.

\section{CONCLUSION}

Since volatile compounds originating from gravure ink and retained in the packaging materials might change the flavour and taste of packed food products, the aim of this study was to evaluate the role of coating in the solvent retention of gravure printed fiber-based packaging materials. To this end, FBB type cardboard samples, with various numbers of coating layers on the top side, and with coated or uncoated back side, were investigated. The coating color thickness per layer, applied to the cardboard surface by the blade coater of the paperboard manufacturing machine, was on average $3.14 \mu \mathrm{m}$. 
The solvent retention was measured by gas chromatography on samples printed by rotogravure. The study had a special focus on the critical solvents: ethanol and ethyl acetate, consequently, the retention ratio of these solvents was calculated. The results were then normalized to coating thickness, in order to see the emission intensity as a function of the number of coating layers applied onto the cardboard surfaces.

The influence of both topside (0, 1, 2, 3 layers) and backside (1 layer) coatings on ethanol and ethyl acetate retention and emission were investigated. It was found that the number of coating layers on the cardboard top and back sides has a clear influence on the solvents retained in the printed packaging and on solvent emission. With an increasing the number of coating layers on the FBB type cardboard coated on both sides, higher amounts of ethanol and ethyl acetate were retained in the substrate and the intensity of solvent emission decreased. Two phases of the ethanol and ethyl acetate evaporation process were determined: the first quick phase - takes 1 day - when the ethanol molecules leave the cardboard coating surface intensively; and the second slow phase - takes 6 days - when the ethanol molecules positioned below the coating layers left the cardboard moderately, and this might be a diffusion controlled process. Presumably, the solvent emission was more obstructed by the coating, when the number of coating layers, and thus the coating thickness, increased. A significant difference was observed when the third coating layer was applied, as it closes more tightly the pores on the cardboard surface, blocking the solvent evaporation.

The diffusion coefficient and solubility parameters of ethanol and ethyl acetate are different and this might have an influence on the evaporation mechanism of these solvents from a polymer structure, as well as on velocity difference between these solvents. The diffusion rate of ethanol is higher than that of ethyl acetate, as the size of the ethyl acetate molecule is considerably larger, so that the ethanol can be released from the cardboard faster, as confirmed by our experiments.

The importance of the coated surface structure, precisely, of the number of coating layers applied, has been clearly confirmed and, thus, cardboard coating has to be considered as a significant variable in solvent retention analysis.

\section{REFERENCES}

$1 \quad$ R. Coles, D. Mcdowell and M. J. Kirwan, in "Food Packaging Technology”, Blackwell Publishing, 2003, https://doi.org/10.1002/jsfa.2089

2 K. A. Barnes, C. R. Sinclair and D. H. Watson, "Chemical Migration and Food Contact Materials", Woodhead Publishing, Cambridge, 2007, https://doi.org/10.1533/9781845692094.1

3 B. Aurela, Academic Dissertation, Oy Keskuslaboratorio-Centrallaboratorium Ab (KCL), Finland, 2001, https://helda.helsinki.fi

4 K. Ridgway, S. P. D. Lalljie and R. M. Smith, Food Addit. Contam., 27, 146 (2009)

5 H. Kipphan, "Handbook of Print Media”, Springer, 2001,

https://www.academia.edu/8722974/Handbook_Of_Pri nt_media

${ }^{6}$ E. R. Todd, in "Printing Inks, Formulation Principles, Manufacture and Quality Control Testing Procedures”, edited by Richard Powell Editorial, 1994

7 R. Szentgyorgyvolgyi, E. Novotny and C. Horvath, in Procs. $40^{\text {th }}$ International Research Conference of IARIGAI: Advances in Printing and Media Technology, Chemnitz, Germany, 08-10 September, 2013, pp. 130-138, http://iarigai.com

8 E. Cawkill and B. A. Ellison, in "The Printing Ink Manual”, edited by R. H. Leach, C. Armstrong, J. F. Brown, M. J. Mackenzie, L. Randall et al., $4^{\text {th }}$ edition, Van Nostrand Reinhold, London, 1988, https://doi.org/10.1007/978-1-4684-6906-6

9 E. Angeli and R. Szentgyorgyvolgyi, Cellulose Chem. Technol., 49, $685 \quad$ (2015), http://www.cellulosechemtechnol.ro/pdf/CCT78(2015)/p.685-691.pdf

10 H. Paulapuro, "Papermaking Science and Technology”, Fapet Oy, 2000, https://www.tappi.org/publications-

standards/books/papermaking-science-and-technologybook-series

11 K. Niskanen, "Mechanics of Paper Products", Walter de Gruyter, 2012, https://www.degruyter.com/

12 K. Niskanen, "Papermaking Science and Technology”, Fapet Oy, 2008, https://www.tappi.org/publications-

standards/books/papermaking-science-and-technologybook-series

13 E. Lehtinen, "Papermaking Science and Technology”, Fapet Oy, Finland, 2000, https://www.tappi.org/publications-

standards/books/papermaking-science-and-technologybook-series

14 H. Holik, in "Handbook of Paper and Board", Wiley-VCH Verlag GmbH \& Co., 2006, https://www.wiley.com

15 P. M. McGenity, P. A. C. Gane, J. C. Husband and M. S. Engley, in Procs. Tappi Coating Conference, 1992, pp. 133, https://www.tappi.org 
16 G. Ström, A. Härdin and P. Salminen, Nordic Pulp Pap. Res. J., 10, $227 \quad$ (1995), https://www.degruyter.com/view/journals/npprj/npprjoverview.xml?lang=en

17 E. Angeli, Sz. Klebert and R. Szentgyorgyvolgyi, in Procs. IJCELIT-4 Conference, Budapest, Hungary, 20-22 November, 2013, pp. 427-435

18 B. Kolb and L. S. Ettre, "Static Headspace-Gas Chromatography”, John Wiley \& Sons, 2006, https://www.wiley.com/en-us

P. Stenius, "Papermaking Science and Technology", Fapet Oy, Finland, 2000, https://www.tappi.org/publications-

standards/books/papermaking-science-and-technologybook-series 